\title{
ÁRVORE GENEALÓGICA DAS PROFISSÕES: UMA ESTRATÉGIA PARA A CONSTRUÇÃO DO PROJETO DE VIDA DE ADOLESCENTES ${ }^{1}$
}

\author{
Genealogical Tree of Professions: A Strategy for the Construction of the \\ Adolescent's Life Purpose \\ http://dx.doi.org/10.21116/2017.4
}

\section{PEREIRA, Patrick}

PUC-Campinas

Centro Universitário de Jaguariúna - UNIFAJ

\section{DELLAZZANA-ZANON, Letícia Lovato}

PUC-Campinas

Resumo: A construção de um projeto de vida (PV) pelos adolescentes pode direcionar seus comportamentos para atividades mais prazerosas e saudáveis, que darão um sentido às suas vidas e uma perspectiva de futuro. Ter um PV também pode afastar os adolescentes de situações nocivas, como uso de drogas e outros comportamentos de risco. Apesar de sua importância, são raras as práticas educativas que têm como objetivo auxiliar os adolescentes a construírem seu PV. O objetivo deste trabalho é apresentar uma atividade desenvolvida em sala com alunos do terceiro ano do Ensino Médio de 2013 a 2017 que visa auxiliar na construção do PV a partir de diálogos com seus familiares. Os adolescentes eram solicitados a construir uma árvore genealógica das profissões dos seus familiares, na qual podiam incluir amigos. A seguir, os adolescentes deviam perguntar para cada indivíduo que inseriu em sua árvore as seguintes questões: Qual profissão seguiu?; Qual profissão queria ter seguido?; Qual profissão admira?; Qual profissão sugere que o adolescente siga? Em outro momento, os resultados das questões sobre a árvore eram apresentados e discutidos com o grupo. Os resultados mostraram que essa atividade promoveu: (a) estreitamento do vínculo com seus familiares; (b) conhecimento de diversas profissões; (c) entendimento das suas expectativas e ansiedades, especialmente quando estas têm relações com as expectativas e ansiedades de seus familiares; (d) elaboração de seu PV com o auxílio do conhecimento e experiência de outras pessoas próximas a eles. Nesse sentido, a árvore genealógica das profissões enfatizou a importância da família para a construção do PV e se mostrou uma estratégia de fácil aplicação e favorável ao desenvolvimento dos projetos de vida dos alunos. Deve-se salientar, no entanto, que outros aspectos devem ser levados em consideração para se pensar o PV do adolescente além da escolha profissional.

Palavras-chave: projeto de vida; adolescência; psicologia escolar.

\footnotetext{
1 Uma versão menor deste trabalho foi apresentado no VIII Seminário Fala Outra Escola: Reexistir nas Pluralidades do Cotidiano, organizado pelo Grupo de Pesquisas em Educação Continuada (GEPEC) da Faculdade de Educação da Unicamp que ocorreu de 25 a 28 de julho de 2017 na Unicamp, Campinas-SP.
} 


\begin{abstract}
The construction of a life purpose (LP) by adolescents can direct their behaviors towards more pleasurable and healthy activities that will give meaning to their lives and a perspective of future. Having a PV can also drive young out of harmful situations, such as drug use and other risk behaviors. Despite their importance, educational practices that are aimed at helping adolescents to build their PV are rare. The objective of this paper is to present an activity developed in a classroom with students from the third year of High School from 2013 to 2017 that aims to assist in the construction of the PV from dialogues with their relatives. The adolescents were asked to build a genealogical tree of the professions of their relatives, in which they could include friends. Next, adolescents should ask each person who inserted the following questions into their tree: What profession followed?; What profession did you want to follow? What profession do you admire?; Which profession suggests that the adolescent follow?. At another time, the results of the tree questions were presented and discussed with the group. The results showed that this activity promoted: (a) closer bonding with family members; (b) knowledge of various professions; (c) understanding of their expectations and anxieties, especially when they have relations with the expectations and anxieties of their family members; (d) elaboration of their PV with the help of the knowledge and experience of others close to them. In this sense, the genealogical tree of the professions emphasized the importance of the family for the construction of the PV and it was a strategy of easy application and favorable to the development of the life projects of the students. It should be noted, however, that other aspects should be taken into account in order to think about the PV of the adolescent beyond the professional choice
\end{abstract}

\title{
INTRODUÇÃO
}

A escola é um espaço importante de interação social (CUNHA, 2007), e possibilita a aquisição de habilidades necessárias para o convívio em sociedade. Dessa forma, a contribuição da escola para a personalidade vai sendo (re)moldada de forma multideterminada pela estrutura do indivíduo, inserida em uma dinâmica constituída histórico-socialmente (VYGOTSKI, 1996). As interações sociais se dão principalmente pelas palavras, e estas "desempenham um papel fundamental, não só no desenvolvimento do pensamento, mas também no desenvolvimento histórico da consciência como um todo" (VIGOTSKI 2000, p. 208).

Dessa forma é importante que os professores planejem atividades que promovam o desenvolvimento de seus alunos por meio de reflexões e da (re)apropriação dos conhecimentos relativos às suas emoções, tornando-os 
próprios do pensamento e da consciência (ANDRADE \& SMOLKA 2012). Nessa premissa, os alunos enquanto pessoas ativas se constituirão sujeitos para o outro e se formarão enquanto indivíduos (LIMA \& CASTRO, 2014) que poderão contribuir com o desenvolvimento do planeta (ONU, 2014).

Tais emoções podem ser o pano de fundo na constituição do projeto de vida (PV), entendido aqui como "uma intenção estável e generalizada de alcançar algo que é ao mesmo tempo significativo para o eu e gera consequências no mundo além do eu" (DAMON, 2009 p. 53). Do ponto de vista do desenvolvimento, a adolescência tem sido considerada como o principal período para se fomentar a elaboração do PV (DAMON, MENON \& BRONK, 2003).

É reconhecida a importância da escola, principalmente por meio da atuação dos professores, na fomentação do PV, no entanto são necessárias mais informações sobre como os professores podem contribuir para a contrução dos PV de seus alunos (BUNDIK \& TIRRI, 2014). A relevância desse dado complementa a problemática de que a falta de Projetos de Vida na juventude pode trazer prejuízos de ordem pessoal e social, como comportamentos destrutivos, baixa produtividade e dificuldade de se manter relações interpessoais (DAMON, 1955). Nesse sentido, o PV é um aspecto importante a ser estudado, pois está relacionado ao desevolvimento saudável da vida (DELLAZZANA-ZANON \& FREITAS, 2015).

Cabe enfatizar a importância da família para que em conjunto com a escola promova a construção do PV. O apoio familiar para o desenvolvimento do PV deve ser dado por meio de uma relação de proximidade que ofereça compreensão, informações, esclarecimentos, oportunidades e conforto emocional, no entanto, nem sempre os pais têm consciência da importância de seu papel, ou sabem como desempenhá-lo de maneira positiva. Nesse sentido a escola pode oferecer momentos para que estas temáticas sejam discutidas com o intuito de instrumentalizar os familiares para lidar com essa esta etapa do desenvolvimento, isto é, a adolescência (LEVENFUS \& NUNES, 2016).

Porém, algumas dificuldades frequentemente enfrentadas pelas escolas podem impactar negativamente no desenvolvimento de seus alunos, 
dentre elas ressaltamos a falta de integração escola-família e a visão do aluno como um consumidor/usuário e não como alguém em desenvolvimento (PEREIRA, MARQUES \& JUSEVICIUS, 2013). Por isso, o objetivo deste trabalho é apresentar uma atividade com enfoque na orientação profissional que visa auxiliar na construção do PV, a partir de diálogos entre adolescentes e seus familiares, o que pode ajudar a superar as dificuldades apontadas acima e contribuir para o desenvolvimento integral do adolescente. Para isso, será descrita de maneira detalhada a realização da atividade "Árvore Genealógica das Profissões", que foi elaborada pelo autor principal deste trabalho para ser aplicada com adolescentes do Ensino Médio.

\section{MÉTODO}

Essa atividade foi realizada em sala, durante o período de 2013 a 2017, com alunos do terceiro ano do Ensino Médio de uma escola privada do interior de São Paulo. Em sala o professor (primeiro autor deste estudo) explicava a relevância e os objetivos da atividade proposta e combinava com os alunos a data da entrega, que em média era de um mês. A atividade consistia na construção de uma árvore genealógica que contemplasse avós, pais, tios, irmãos, primos e amigos, para os alunos que desejassem. Apesar de amigos não constituírem a genealogia original dos alunos, eles podiam ser incluídos devido à importância afetiva que têm e a influência que exercem sobre as escolhas de seus pares.

A árvore deveria ser montada preferencialmente em forma de fluxograma, mas os alunos eram livres para escolherem seu layout. Considerando a diversidade e a dimensão da família brasileira, alguns membros poderiam ficar de fora, como, por exemplo, tios distantes e primos com quem os alunos tinham pouco contato. Deixar isso claro era importante, para que a atividade não fosse exaustiva para os alunos que tinham famílias muito grandes. Além disso, não se espera que familiares que tem pouco ou nenhum contato com os alunos possam contribuir de maneira significativa para a construção de seu PV. 
Para cada pessoa incluída na árvore, o aluno deveria fazer e registrar as seguintes perguntas:

(a) Qual profissão seguiu?

Objetivo: ajudar o adolescente a conhecer as trajetórias profissionais de seus familiares e ter acesso a diferentes perspectivas no planejamento de sua carreira, a partir da experiência de vida das pessoas próximas a ele.

(b) Qual profissão queria ter seguido?

Objetivo: promover a reflexão sobre os entraves encontrados pelos seus próprios familiares para se conquistar a profissão desejada, auxiliando na elaboração de estratégias que previnam um planejamento mal elaborado.

(c) Qual profissão admira?

Objetivo: revelar as expectativas dos familiares pelos seus adolescentes e as contradições entre o caminho seguido e o desejado.

(d) Qual profissão sugere que eu siga?

Objetivos: revelar ou confirmar os anseios dos familiares quanto à carreira dos estudantes; abrir um espaço de diálogo entre os familiares e o adolescente para que este se manifeste a respeito de seu próprio desejo; e ajudar o adolescente a perceber suas potencialidades a partir do olhar do outro.

Além dos objetivos específicos de cada pergunta, a atividade proposta tinha como objetivos: (a) aumentar o conhecimento do aluno a respeito da história de sua família, (b) auxiliá-lo a planejar sua própria história, (c) possibilitar a aproximação com os membros de sua família e (d) possibilitar a reflexão quanto às inúmeras possibilidades profissionais e sua relação com a família. As questões feitas pelos adolescentes a seus familiares também permitiam que os familiares recuperassem sua própria história, seus sonhos e suas dificuldades, e se colocassem no lugar dos seus descendentes, permitindo-os fazer suas próprias escolhas, agora com mais propriedade, 
possibilitando o seu desenvolvimento histórico como um todo (VIGOTSKI, 2000).

Orientou-se aos adolescentes que se algum familiar falecido fosse importante para sua constituição enquanto pessoa, e fosse incluido na árvore, o próprio adolescente poderia responder às perguntas se imaginando no lugar desse familiar ou poderia solicitar que outro parente próximo ao falecido o fizesse. Nesse caso, as respostas revelariam o imaginário a respeito de tal pessoa que ainda se fazia presente para o jovem.

No dia da entrega fazia-se uma devolutiva coletiva com as principais experiências, conhecimentos e reflexões adquiridas com as entrevistas. Com as atividades em mãos os alunos que desejassem poderiam comentar como tinha sido sua experiência, assinalando: (a) como foi a execução da atividade; (b) o que descobriu sobre sua família; (c) como as entrevistas foram realizadas (por exemplo, se visitaram ou telefonaram para); (d) o que acharam das respostas (se era o que esperavam ou se teve alguma surpresa; (e) se a realização das entrevistas contribuiu para a construção de seu PV.

Assim os alunos poderiam trocar o que aprenderam e se aproximarem enquanto grupo pela identificação com as histórias uns dos outros e foi possível conhecer o contexto em que vivem, bem como suas necessidades e perspectivas, o que possibilita a criação de estratégias que favorecem comportamentos saudáveis $(\mathrm{Li}, 2011)$ pelo processo de interação entre 0 indivíduo biopsicossocial dotado de potencialidades e o contexto sociocultural em que vive, promovendo o Desenvolvimento Juvenil Positivo (SCHMID \& LOPEZ, 2011).

Em seguida eles entregavam as atividades para leitura posterior do professor, que em momentos individuais intra ou extraclasse auxiliava os estudantes a fazerem uma leitura geral da árvore, contextualizando as relações familiares com os sentimentos dos próprios adolescentes, como expectativas, idealizações, medos, perspectivas e desejos, enriquecendo exponencialmente os resultados da atividade e melhorando sua relação com os alunos. 


\section{RESULTADOS E DISCUSSÃO}

Essa atividade foi aplicada com a terceira série do Ensino Médio nos anos de 2013 a 2017 em uma escola privada do interior do estado de São Paulo, totalizando 5 turmas com aproximadamente 20 alunos cada, com excessão da turma de 2017, que contou com 8 participantes. A realização mostrou-se importante para a promoção do projeto de vida (PV) não apenas no âmbito profissional, mas também pessoal e familiar. A maioria dos alunos se empenhou na realização das entrevistas e na elaboração da árvore, embora nem todos tenham optado pela construção do fluxograma. Outras formas de organização, como tópicos e desenhos com legendas atingiram o objetivo da atividade e permitiram uma organização, leitura e interpretação dos dados.

Quase nenhum aluno incluiu pessoas falecidas na árvore, enquanto que quase todos incluíram amigos, revelando a importância das amizades para construção do PV nessa faixa etária, o que indica as possibilidades de mudanças que esses jovens estão exprienciando. Essas mudanças podem fortalecer a concepção tradicional dessa etapa como um risco (SCHOENFERREIRA \& AZNAR-FARIAS, 2010), ou pode ser considerada como uma oportunidade para fazer florescer o desenvolvimento juvenil de maneira positiva, ao oferecer contingências ao indivíduo que reforcem ou possibilitem comportamentos saudáveis ( $\mathrm{Li}, 2011)$.

Cabe ressaltar que a maioria dos familiares respondeu "a que te fizer feliz" ou "a que você quiser" para a pergunta 4 - qual profissão sugere para você seguir? - centrando a responsabilidade da escolha profissional no adolescente e na ideia da felicidade. Esse tipo de resposta pode fortalecer a escolha do jovem, ao mesmo tempo em que pode gerar insegurança, uma vez que este não tem subsídios suficientes para ter certeza de que gostará de executar a profissão escolhida.

Por isso é importante a atuação do professor no auxilio às famílias, que muitas vezes não sabem como lidar com essa temática (LEVENFUS \& NUNES), e aos alunos que para que consigam prever as consequências de suas ações e elaborar um PV para além da escolha profissional, isto é, que 
tenha um significado e uma importância para além de si (ARAUJO et. al, 2016; DAMON, 2009).

Outro ponto de destaque foi a grande variedade de respostas às perguntas quanto às profissões colocadas, sendo que mais da metade apontava profissões diferentes para cada uma das perguntas, o que pode revelar que grande parte dos familiares não seguiu a profissão que desejava e nem a que admira, sendo ambas diferentes da que sugere para o jovem, talvez por este relatar o desejo ou habilidade para uma profissão diferente.

Em todos os anos ouviram-se relatos de curiosidades familiares, histórias, assim como medos e anseios sobre os quais os adolescentes não tinham conhecimento. Essa troca de saberes possibilitou a aproximação entre eles e suas famílias, pela abertura de um espaço de diálogo que até então não existia. No geral os pais sugeriram alguma profissão baseada em sua própria experiência de vida e no perfil de seu filho(a), mas deixavam claro que a felicidade deste(a) estava em primeiro plano, dando mais segurança para que 0 adolescente fizesse sua própria escolha.

A resposta às perguntas, em grande parte das vezes veio acompanhada de relatos de experiência, que permitiram o aprofundamento da rotina profissional, o que aumentou ou diminuiu o interesse por determinadas profissões. Esses relatos eram contados em sala pelos alunos no momento da devolutiva em grupo, e despertavam o interesse e atenção dos outros alunos, constituindo-os como sujeitos ativos para o outro e se formando enquanto indivíduos (LIMA \& CASTRO, 2014).

Outro fator importante é que a maioria dos alunos tinha familiares cuja profissão não exigia Ensino Superior, e eram admirados pelos adolescentes enquanto pessoa e profissional. Essa constatação abriu espaço para a reflexão de que o caminho universitário não é o único possível, e que a conclusão da primeira graduação não cristaliza outras possibilidades profissionais.

Os familiares mais admirados tinham por característica a realização pessoal e uma presença ativa e afetiva nas relações familiares. A possibilidade de se espelhar em alguém que se importa com sua família tange à ideia de se preocupar com o outro, o que se configura como um fator de proteção contra 
comportamentos autodestrutivos, como o uso de drogas (ABRAMOSKI et. al., 2017) e o leva a refletir sobre o mundo à sua volta e como eles almejam contribuir com a sociedade em que vivem (DAMON, 2004).

Os resultados dessa atividade reverberaram para além da escolha profissional, e permitiram que os adolescentes refletissem com seus familiares e com seus pares sobre as possibilidades e dificuldades com que se depararam. A relação entre carreira, satisfação pessoal e constituição familiar, além de fortalecer a imagem pessoal, contribui para a elaboração do PV de maneira geral, uma vez que este é construído na relação indivíduo/sociedade, na qual o indivíduo interage com o mundo e a alteridade, num processo contínuo e dinâmico de reconstrução das representações sociais (MARCELINO, CATÃO \& LIMA, 2009).

Essa atividade abriu espaço para a palavra dos adolescentes e seus familiares, que traziam "em si as marcas das enunciações anteriores, as marcas de sua história enunciativa concreta, pois ao ser enunciada, a palavra traz em si sua significação histórica e culturalmente constituída" (PRADO, 2013 p.151). Dessa maneira, os adolescentes se apropriaram mais de sua própria história, e como consequência puderam se projetar com mais segurança para o futuro, a partir do resgate da sua história familiar feita por (e em conjunto com) seus familiares, que também tiveram a oportunidade de refletir sobre suas próprias vidas com o cruzamento dos três tempos, o que foram, o que são e o que querem ser, remoldando e recuperando sua própria identidade (GUEDESPINTO, 2002).

\section{CONSIDERAÇÕES FINAIS}

Para que a escola enquanto ambiente consiga auxiliar seus alunos a desenvolverem o PV, é necessário que pensem em atividades que levem os estudantes a preverem as consequências de suas ações para além si.

O objetivo deste trabalho, enquanto relato de casos, foi apresentar uma atividade desenvolvida em sala com alunos do terceiro ano do Ensino Médio que visou auxiliar na construção do projeto de vida (PV) com enfoque na escolha profissional, a partir do diálogo com seus familiares. A atividade 
apresentada além de atender o seu objetivo, também proporcionou outras reflexões para além da escolha profissional.

Os alunos também tiveram a oportunidade de conhecer diferentes histórias de vida e perspectivas dentro e fora do âmbito familiar. Dessa maneira foi possível aumentar a segurança de suas escolhas e promover a construção do seu PV contribuindo com seu Desenvolvimento Juvenil Positivo pelo processo de interação entre 0 indivíduo biopsicossocial dotado de potencialidades e o contexto sociocultural em que vive.

É importante difundir esse tipo de atividade, pois além de ser de fácil aplicação e exigir pouco recurso financeiro/material, ela instrumentaliza o professor para que ele auxilie seus alunos na construção do PV. Como consequência, isso contribui para a redução dos comportamentos de risco típicos da adolescência e para o desenvolvimento saudável desses jovens, auxiliando-os na projeção de seu futuro e na sua relação com seus familiares e amigos.

Cabe ressaltar que apenas uma atividade, por mais elaborada que seja, é insuficiente para colaborar de forma plena na construção do PV de adolescentes, uma vez que essa construção é o resultado de um processo que envolve várias etapas e momentos históricos do indivíduo. Por isso, outras atividades foram executadas antes dessa, desde a primeira série do Ensino Médio e depois quando eles estão se preparando para sair da escola. Como exemplo, podem-se citar as seguintes: (a) rodas de conversa sobre temas diversos solicitados pelos alunos, como; mercado de trabalho, concepções e modelos familiares, sexualidade, drogas lícitias e ilícitas, autoestima e autoconfiança; (b) rodas de conversa com ex-alunos que estão na faculdade e/ou inseridos no mercado de trabalho; (c) entrevistas com profissionais externos sobre sua trajetória profissional; (d) entrevistas com os professores da escola sobre sua trajetória profissional; (e) busca por currículos escolares e linhas de pesquisa de diferentes instituições de Ensino Superior; e (f) construção da linha do tempo desde o nascimento até o momento atual. 


\section{REFERÊNCIAS}

ABRAMOSKI, $\mathrm{K}$ et. al. Variations in Adolescent Purpose in Life and Their Association With Lifetime Substance Use. The Journal of School Nursing. N. 1 mar. 2017. Doi: $10.1177 / 1059840517696964$

ANDRADE, J.de J. de \& SMOLKA, A. L. B. Reflexões sobre desenvolvimento humano e neuropsicologia na obra de Vigotski. Psicologia Estudos, Maringá, v. 17, n. 4, p. 699-709, dez. 2012.

ARAUJO, U. F., et. al. Principles and methods to guide education for purpose: a Brazilian experience. Journal of Education for Teaching, 42(5), 556-564. 2016. https://doi.org/10.1080/02607476.2016.1226554

BUNDICK, M. \& TIRRI, K.. Student Perceptions of Teacher Support and Competencies for Fostering Youth Purpose and Positive Youth Development: Perspectives From Two Countries. Applied Developmental Science, v 18 (3) p. 148-162, 2014.

CUNHA, R. B. Lembranças de Escola na Formação Inicial de Professores. In: PRADO, G. do V. T. \& CUNHA, R. B. (orgs.). Percursos de Autoria: Exercícios de Pesquisa. Campinas: Alínea, 2007. Cap. 4.

DAMON, W. O que o Jovem quer da Vida? Como Pais e Professores podem orientar e motivar os adolescentes. São Paulo: Summus Editorial, 2009.

DAMON, W. What is positive youth development? The Annals of the American Academy of Political and Social Science, 591(1), 13-24. 2004.

DAMON, W.; MENON, J. \& BRONK, K. C.. The Development of Purpose During Adolescence. Apllied Developmental Science. v. 7, n 3, p.119-128, 2003.

DAMON, W. Greater Expectations: overcoming the culture of indulgence in our homes and schools. New York: Free Press. 1995.

DELLAZZANA-ZANON, L. L. \& FREITAS, L. B. de L. Uma Revisão de Literatura sobre a Definição de Projeto de Vida na Adolescência. Interação Psicologia, Curitiba, v. 19, n. 2, p.101-122. 2015.

DELLAZANA-ZANON, L. L.; RITER, H. da S. \& F., L. B. de L.. Projeto de Vida de Adolescentes que Cuidam e que não Cuidam de seus Irmãos Menores. In: MACEDO, Rosa Maria Stefanini de. Expandindo Horizontes da Terapia Familiar. Curitiba-PR: CRV, Pág. 101-122. 2015. 
GUEDES-PINTO, A. L. Memorial de formação - Registro de um percurso. 2002.

<http://www.fe.unicamp.br/ensino/graduacao/downloads/proesf-

AnaGuedes.pdf>. 03/04/2016.

LEVENFUS, R. S. \& NUNES, M. L. T. A Família e a Construção de Projetos de Vida. In: LEVENFUS, R. S. (org.). Orientação Vocacional e de Carreira em Contextos Clínicos e Educativos. São Paulo: Artmed, 2016. Cap. 2.

LI, Y. School engagement. What it is and why it is important for positive youth development. Advances in Child Development and Behavior. Elsevier Inc. 1 ed., Vol. 41, 2011. https://doi.org/10.1016/B978-0-12-386492-5.00006-3

LIMA, E. Ap. de \& CASTRO, R. M. de. Narrativas e Atividade Docente: Perspectivas e Desafios Metodológicos para a Pesquisa em Educação e Formação de Professores. Diálogo Educ., Curitiba, v. 14, v. 41, p. 81-100, jan/abr. 2014.

MARCELINO, M. Q. dos S.; CATÃO, M. de F. F. M.; LIMA, C. M. P. de. Representações Sociais do Projeto de Vida entre Adolescentes no Ensino Médio. Psicologia Ciência e Profissão, Brasília, v. 29, n3, p. 544-557, 2009.

ORGANIZAÇÃO DAS NAÇÕES UNIDAS (ONU). Adolescentes e jovens são $\mathbf{2 8 \%}$ da população mundial; ONU pede mais investimentos, 2014. Disponível em: https://nacoesunidas.org/adolescentes-e-jovens-sao-28-da-populacaomundial-onu-pede-mais-investimentos/. Acesso em: 08 out. 2017.

PEREIRA, P.; MARQUES, C. A. E.; JUSEVICIUS, V. C. C.. A Ação dos Professores diante dos Conflitos entre Alunos. Intellectus Revista Acadêmica Digital, Jaguariúna, n. 25, p. 215-237, out./dez. 2013.

PRADO, G. do V. T.. Narrativas Pedagógicas: indícios de conhecimentos docentes e desenvolvimento profissional. Interfaces da Educação, Parnaíba, v. 4, n. 10, p.149-165, 2013.

SCHMID, K. L., \& J. LOPEZ, S. Positive pathways to adulthood. In Advances in Child Development and Behavior. 1 ed., pp. 69-88, 2011. https://doi.org/10.1016/B978-0-12-386492-5.00004-X.

VYGOTSKY, L. S. Pensamento e Linguagem. São Paulo: Martins Fontes, 2000.

VYGOTSKY, L. S. Problemas de la Psicologia Infantil. In: Obras escogidas (6 volúmenes), tomo IV. Madrid: Visor/MEC, 2016. Pág. 249-386. 


\section{Sobre os Autores:}

Patrick Pereira: Psicólogo (UNIFAJ, 2012), Psicopedagogo (UNIFAJ, 2016) e Mestrando em Psicologia (PUC-CAMPINAS). Atua como Psicólogo Clínico e Escolar; trabalha no setor de pesquisa do Centro Universitário de Jaguariúna UNIFAJ. Membro do Grupo de Estudos de Mobilidade e Acessibilidade para Cidades Saudáveis (GEMOBIAS) e do Grupo De Estudos De Promoção Da Saúde E Qualidade De Vida (GEPV) da UNIFAJ.

E-mail: contato@patrick.psc.br

Letícia Lovato Dellazzana-Zanon: É Psicóloga (PUCRS, 2001), Especialista em Terapia de Família e Casal (Domus, 2004), Mestre em Psicologia (UFRGS, 2008) e Doutora em Psicologia (UFRGS, 2014). É Professora do Programa de Pós-Graduação em Psicologia e do Curso de Graduação em Psicologia da PUC-Campinas. É pesquisadora do grupo de pesquisa Psicologia da Saúde e Desenvolvimento da Criança e do Adolescente do Programa de PósGraduação em Psicologia e do Curso de Graduação em Psicologia da PUCCampinas. É membro do grupo de trabalho Avaliação em Psicologia Positiva e Criatividade da Associação Nacional de Pesquisa e Pós-graduação em Psicologia (ANPEPP). É colaboradora do Laboratório de Psicologia e Epistemologia Genética (LAPEGE/UFRGS). Atua na área de Psicologia do Desenvolvimento, com ênfase em desenvolvimento do adolescente e construção do projeto de vida

E-mail: leticiadellazzana@gmail.com 